\title{
Air-breathing Microfluidic Fuel Cell with Fuel Reservoir
}

\author{
Seyed Ali Mousavi Shaegh ${ }^{\mathrm{a}, \mathrm{b}}$ Nam-Trung Nguyen ${ }^{\text {a,b }} \quad$ Siew Hwa Chan ${ }^{\mathrm{a}, \mathrm{b}}$ \\ ${ }^{a}$ School of Mechanical and Aerospace Engineering, Nanyang Technological \\ University, 50 Nanyang Avenue, Singapore 639798, Singapore \\ ${ }^{\mathrm{b}}$ Energy Research Institute at NTU (ERI@N), Singapore 637553, Singapore
}

Tel: (0065) 6790-4457 Fax: (0065)6791-1859

*Corresponding author

\begin{abstract}
This paper describes the design and characterization of an air-breathing microfluidic fuel cell with a stationary fuel reservoir above the anode replacing the continuous fuel stream. Unlike other air-breathing microfluidic designs, the fuel is not in direct contact with electrolyte stream allowing the use of high fuel concentration. In addition, Ohmic losses are minimal because of the low anode-to-cathode spacing. Since the fuel passes through the catalyst layer of the anode, the conventional depletion boundary layer does not form. Improved mass transport compared to previous microfluidic designs is obtained because of a supply of a uniform fuel concentration over the anode and efficient bubble removal from the anode active sites. For practical applications, the fuel reservoir can be replaced by a pressurized fuel cartridge. The pressure is optimized according to the fuel concentration and the power density. This simple design of the fuel cell provides a low-cost but functional platform for practical applications.
\end{abstract}

Key words: Fuel cell, Membraneless, Microfluidic, Fuel utilization, Porous electrode, Graetz number. 


\section{Introduction}

Microfluidic fuel cells [1-3] generally exploit the laminar streams of a fuel and an oxidant in an aqueous supporting electrolyte. The concept is implemented in a microchannel where electrodes are located on the channel walls. Charge transport between the electrodes occurs inside the channel and through the confined co-laminar liquid-liquid interface [4-5]. In addition to microfluidic fuel cells running on both aqueous fuel and oxidant streams, integration of a gas diffusion electrode (GDE) as an air-breathing cathode in a microfluidic fuel cell allows the fabrication of an air-breathing microfluidic fuel cell [6]. Because of the high concentration and high diffusion coefficient of oxygen in the ambient air [6], the usually low maximum power density of less than $10 \mathrm{~mW} \mathrm{~cm}^{-2}$, dominated by the low concentration of dissolved oxygen [2,7], can be improved to a value of about $100 \mathrm{~mW} \mathrm{~cm}^{-2}$ [8-9].

Since ion exchange membrane is eliminated from the design of a microfluidic fuel cell, a vast range of fuels and oxidants in alkaline or acidic electrolytes can be exploited $[7,8]$. Similar to a membrane-based fuel cell, the performance is determined by the combination of activation, Ohmic and mass-transport overpotentials [10]. Because of the laminar nature of the reactants streams in the channel, interaction of reactant-electrode plays an important role on decreasing the mass transport losses $[11,12]$.

Various flow architectures for microfluidic fuel cells have been examined to manipulate the physico-electrochemical phenomena to improve the reactant utilization and the maximum power density $[9,10,13-16]$. In order to provide a methodological approach for reviewing the studied flow architectures available in the literature we followed a dimensionless analysis. In a microfluidic fuel cell, reactants are directed to a fluidic channel with reactive walls by a convective flow in which reactants diffuse to the catalytic sites over the walls. The steadystate diffusion-limited mass transport to a reactive site in a pressure-driven flow is known as the Graetz problem and it is usually divided into two main operation regimes of the entrance 
regime and the fully developed regime [17]. Graetz number $\left(G z \equiv z h^{-1} P e^{-1}\right)$ represents the ratio of convective time scale $\left(\overline{t_{c}}=z U^{-1}\right)$ to diffusive time scale $\left(\overline{t_{d}}=h^{2} D^{-1}\right)[17]$, where $z$ is the axial position along the channel and $h$ is the channel height which determines the diffusion length scale. $P e$ represents Peclet number $\left(U h D^{-1}\right)$ and $U$ is the axial flow velocity in the channel [17].

For a given design of a microfluidic fuel cell with flow-over electrodes, consumption of fuel and oxidant forms a region with low reactant concentration over the electrodes $[18,19]$. As reactant flow rate increases, diffusion time scale becomes much greater than the axial convective time scale, resulting in a diffusion-limited performance meaning $G z<<1$, as shown in Figure 1. In this case, a thin depletion boundary layer $(\delta)$ over the electrode $(\delta<<$ $h)$ is formed and a mass transfer entrance region appears [17]. Running on a high flow rate of reactant, a high power density is obtained from a cell, but because of rapid convective mass transport to the cell outlet and lack of a transverse mass convection across the channel, a portion of the reactant can't reach the reactive sites by diffusion. Therefore, low reactant consumption is achieved and the performance becomes diffusion dominated. An example of the formation of an entrance regime can be found in [19] while the fuel cell was running on high flow rate of $500 \mu 1 \mathrm{~min}^{-1}$.

As reactant flow rate decreases, more residence time within the channel is provided. Consequently, reactant utilization improves and a bulk depletion of reactants takes place through the channel which results in a mass transfer fully developed region. In this mass transfer regime, reactant consumption is high, but power density drops compared to operation in higher flow rates, as shown in Figure 1. A similar example can be found for formic acid depletion in a cell running on a flow rate of $10 \mu 1 \min ^{-1}[19]$.

\section{$<$ Figure 1>}


Transition from regime of entrance region which occurs at high flow rates to operation at regime of fully developed region at low flow rates reveals a trade-off between power density and fuel utilization exists which has been reported frequently [19-22].

To facilitate the optimization of fuel utilization and power density together, interaction between mass transport and electrochemical reactions should be considered as well. Damköhler number is defined as the ratio of the time taken by the mass transport to the time taken by the reaction over the reactive sites [17]. For a purely-diffusive mass transport, Damköhler number is defined as $D a=k C^{X-1} h D^{-1}$, where $k, C, X$ and $D$ are the rate constant, concentration, order of reaction and the diffusivity of a particular reactant. To evaluate the effect of flow architecture on the cell performance, three designs of fuel cells running on all vanadium redox solutions as fuel and oxidant were selected, Figure 1. The vanadium redox fuel and oxidant provide a well-balanced electrochemical half cells for reaction rates and transport kinetics without using catalyst [10]. Three designs have different electrode structures and flow architectures. The one with planar flow-over graphite rod electrodes has a diffusion length of $150 \mu \mathrm{m}(h=150 \mu \mathrm{m})$ [22], while the another one has flow-over porous electrodes with a diffusion length of $120 \mu \mathrm{m}(h=120 \mu \mathrm{m})$ [23]. For the design with flowthrough porous electrodes, since the whole stream of reactants pass through the porous electrode [3], diffusion length of $36 \mu \mathrm{m}(h=36 \mu \mathrm{m})$ has been assumed which is the average fiber spacing of the porous carbon paper-based electrodes [23].

In order to improve reactant utilization, diffusion length scale from the bulk stream to the reactive sites should be decreased by manipulating the flow architecture. Decreasing the reactants flow rate or channel height or using porous electrodes decreases the diffusion length scale. As depicted in Figure 1, decreasing the diffusion length scale increases maximum power density and fuel utilization per single pass at a given flow rate. Maximum improvement in terms of power density and fuel utilization is achieved for the design with 
flow-through porous electrodes. This performance improvement is an indication of enhanced mass transport through the extended reactive sites of the porous electrodes with continuous replenishment of depleted reactants.

In order to decrease the diffusion length scale, Jayashree et al.[20] attempted to exploit hydrodynamic focusing with co-laminar streams of fuel and electrolyte to create a thin layer of formic acid stream over a planar flow-over electrode for an air-breathing cell. Xuan et al. [21] used this concept in a numerical simulation of a fuel cell running on both-aqueous fuel and oxidant streams using a buffer stream.

Another method to decrease the diffusion length scale is the generation of chaotic mixing through the channel using microridges patterned in the reactive area $[12,18]$. In this way, the depletion boundary layer is replenished by the fresh reactant provided from the middle of the channel and fuel utilization is improved. Depending on the fluidic design of the cell with chaotic mixing, the interdiffusion mixing of co-laminar streams in the channel is enhanced [18] or the fluidic complexity is increased if a counter-flow microfluidic platform is exploited [12].

In order to improve the fuel utilization and power density in an air-breathing fuel cell running on formic acid, Shaegh et al. [11], used porous carbon-paper electrodes for flow-over and flow-through architectures as shown in Figure 2. Chronoamperometry results revealed that cell current density is improved because of the facilitated replenishment of the consumed reactants in the flow-through porous anode compared to the planar flow-over electrode [11]. Through dehydrogenation pathway of formic acid electrooxidation, which is known as the direct and favorite pathway [24], carbon dioxide is generated as shown in equation (1):

$$
\mathrm{HCOOH} \rightarrow \mathrm{CO}_{2}+2 \mathrm{H}^{+}+2 \mathrm{e}^{-} \quad \mathrm{E}^{\mathrm{o}}=-0.199 \mathrm{~V} \text { vs SHE }
$$

Since fuel utilization is increased in a cell with the flow-through anode [11], the chance of formation of carbon dioxide bubble in the flow channel increases which can hinder fuel 
transport to the anode active sites and disturb the fuel-electrolyte interface. In addition, bubble formation in the channel increases the total Ohmic loss [25] because of the reduced area available for charge transport between the electrodes.

An air-breathing microfluidic fuel cell should be able to operate at medium to low flow rates with high power density and fuel utilization. But in the case of using formic acid or methanol which are widely available in high concentrations, removal of reaction products and bubbles from the active sites becomes difficult as flow rate decreases [11]. In addition, because of the large interface between the fuel and the electrolyte stream and the subsequent diffusion mixing and fuel crossover in the current designs, utilization of fuel with high concentration degrades the cell performance dramatically [6]. Breaking this trade-off needs a different solution for air-breathing microfluidic fuel cell.

$<$ Figure 2 $>$

To address the above issues we propose in this paper a design of air-breathing microfluidic fuel cell with fuel reservoir above the anode and a stream of electrolyte in the fluidic channel, Figure 3. A uniform fuel concentration is supplied over the reactive sites of the anode and the generated bubbles can be released freely to the fuel reservoir.

\section{Fabrication}

The anode was made of plain Toray carbon-fiber-based paper with a typical thickness of $280 \mu \mathrm{m}$ and a porosity of approximately $78 \%$. This carbon paper was originally used as gasdiffusion-electrode for proton exchange membrane fuel cells (PEM fuel cells). The anode contains a catalyst layer made of palladium black (Pd) with a loading of $7-8 \mathrm{mg} \mathrm{cm}^{-2}$ [11]. To make the catalyst ink, high-surface-area Pd black particles (99.9\% metal basis) from AlfaAesar were mixed with carbon nanoparticles (Vulcan X72) with a loading of $1 \mathrm{mg} \mathrm{cm}^{-2}$ to improve the Pd particles dispersion. Nafion solution with a loading of $3 \mathrm{mg} \mathrm{cm}^{-2}$ was used as 
a binder. To obtain an appropriate viscosity, isopropanol was added to the mixture followed by ultrasound sonication for 1 hour. The obtained catalyst ink was spread over a piece of carbon paper with a size of $10 \times 10 \mathrm{~cm}^{2}$ manually and dried under a fume hood for 20 minutes and subsequently kept in an oven at a temperature of $80{ }^{\circ} \mathrm{C}$ for 1 hour. The cathode was made of carbon-fiber-based paper as used in our previous work [11]. The cathode was purchased from Alfa Aeser (stock No. 45375) which is originally designed to be used as a cathode for direct methanol fuel cells.

The microfluidic fuel cell consists of a $0.5 \mathrm{~mm}$-thick silicon-rubber layer to form the flow channel. Similar to the designs reported in Ref. [11] channel has a length and width of $30 \mathrm{~mm}$ and $3 \mathrm{~mm}$, respectively. The channel depth is determined by the thickness of the silicon rubber. It was cut using a $\mathrm{CO}_{2}$ laser machining system (Universal M-300 Laser Platform, Universal Laser Systems Inc.). Since the channel is made of a flexible silicon rubber, the device is self-sealing.

As shown in Figure 3, in order to accommodate the electrodes in the current collectors, a slit was machined into the same graphite plates using a desktop three-dimensional milling machine (Roland ${ }^{\circledR}$ DG Corporation, model MDX-40A). Electrode strips were fixed on the edges of the slit using a conductive epoxy containing silver particles (CircuitWorks ${ }^{\circledR}$ Conductive Epoxy from Chemtronics $\left.{ }^{\circledR}\right)$. Both electrodes were aligned with the channel to maintain $0.9 \mathrm{~cm}^{2}$ anodic and cathodic catalytically-active surface area. The flow channel was sandwiched between two graphite current collectors. Fluidic interconnects for handling the streams were glued to the graphite plates using a fast drying epoxy. The fabricated cell was inspected for leakage using DI water from Millipore.

\section{$<$ Figure 3 $>$}

\section{Characterization}


The oxidation reaction of formic acid over platinum-group metals can follow two pathways. Through the dehyrogenation pathway, which is known as the direct and favorite path, active species of $\mathrm{H}^{+}$are generated and electrons are released, as shown in equation (1). Through the dehydration pathway, poisoning intermediates such as $\mathrm{CO}$ are produced and block the active sites for direct pathway. Oxidation of formic acid on Pd surfaces mostly proceeds through the dehydrogenation reaction step [24]. Produced protons travel across the channel by diffusive transport because of a gradient in proton concentration between the anode and the cathode, and by electromigration because of the voltage gradient between the electrodes [13].

Oxygen is supplied through the gas-diffusion cathode from the ambient air. Without considering different reaction intermediates, oxygen reduction reaction (ORR) occurs as:

$\mathrm{O}_{2}+4 \mathrm{H}^{+}+4 \mathrm{e}^{-} \rightarrow 2 \mathrm{H}_{2} \mathrm{O} \quad \mathrm{E}^{\mathrm{o}}=1.229 \mathrm{~V}$ vs SHE

The fuel cell characterization tests were done using fuel containing formic acid with $1 \mathrm{M}$ and $3 \mathrm{M}$ concentrations including $0.5 \mathrm{M}$ sulfuric acid as a supportive electrolyte and a stream of $0.5 \mathrm{M}$ sulfuric acid as the electrolyte stream. The flow rate of the electrolyte stream was kept constant for all experiments. Electrolyte stream was delivered by a syringe pump (KD Scientific). Fuel was supplied from the chamber above the anode where it was exposed to the anodic catalyst layer directly. Performance of the fuel cell was characterized under two conditions of atmospheric pressure and gauge pressure of 3 mbar. For all experiments running under the condition of gauge pressure, with the purpose of avoiding fuel crossover to the cathode side, electrolyte was first introduced into the flow channel using a syringe pump. Then, the chamber was filled with the fuel and connected to the pressure regulator (PPC4-ui, Fluke, USA). Figure 4 shows the changes of open-circuit potential after filling the fuel reservoir. For all experiments, the open-circuit potential (OCV) was monitored until it reached a stable value. 
In order to capture the effect of active mechanisms inside the cell such as $\mathrm{CO}_{2}$ generation, a potential scanning rate of $5 \mathrm{mV} \mathrm{s}^{-1}$ with a potential step of $0.01 \mathrm{~V}$ were selected [11]. All the characterization tests were carried out at a room temperature of $25{ }^{\circ} \mathrm{C}$. Current at different cell potentials was measured with an electric load system (PGSTAT 302 with GPES Manager as interface software). To evaluate the combined Ohmic cell resistance, electrochemical impedance spectroscopy (EIS) was carried out at the open-circuit potential (OCV) [11]. Frequency range of EIS was from $0.1 \mathrm{~Hz}$ to $500 \mathrm{kHz}$ with an $\mathrm{AC}$ amplitude of $10 \mathrm{mV} \mathrm{rms}$.

\section{$<$ Figure 4>}

\section{Results and discussions}

As shown in Figure 5, a total cell resistance of $0.55 \pm 0.10 \Omega$ was obtained from the intercept of high-frequency impedance spectrum with real axis. This is almost one third of our previous design with a flow-through porous anode $(1.83 \pm 0.33 \Omega)$ and a channel depth of $1.5 \mathrm{~mm}$ [9]. Since the fuel stream is eliminated from the channel, anode-to-cathode spacing and the corresponding electrolyte ionic resistance across the flow channel decreases.

$<$ Figure 5 $>$

Figure 6 compares the performance of the fuel cell under two conditions. At atmospheric pressure, mass transport overpotential dominates the cell performance at a current density of $50 \mathrm{~mA} \mathrm{~cm}^{-2}$ and a maximum power density of $14 \mathrm{~mW} \mathrm{~cm}^{-2}$ was obtained. The behavior is characteristic for a mass transport-limited operation, because of the purely-diffusion mass transport to the reactive sites. At a gauge pressure of 3 mbar, a limiting current density of $140 \mathrm{~mA} \mathrm{~cm}^{-2}$ and a maximum power density of $29 \mathrm{~mW} \mathrm{~cm}^{-2}$ were achieved. Higher maximum power density is an indication of improved mass transport to the active sites. The open-circuit potential of the cell running under gauge pressure was observed to drop slightly. This effect can be associated with the fuel crossover to the cathode side. 
To investigate the effect of fuel concentration on the cell performance, $1 \mathrm{M}$ and $3 \mathrm{M}$ formic acid were used as fuels. The gauge pressure of the fuel reservoir was kept constant at 3 mbar for both concentrations. A maximum power density of $18 \mathrm{~mW} \mathrm{~cm}^{-2}$ was obtained using $1 \mathrm{M}$ formic acid which is quite comparable with the maximum power density of $20 \mathrm{~mW} \mathrm{~cm}^{-2}$ from our previous flow-through design running on $100 \mu 1 \mathrm{~min}^{-1}$ [11]. Figure 7 clearly shows that increment of fuel concentration from $1 \mathrm{M}$ to $3 \mathrm{M}$ can improve the current density from $18 \mathrm{~mW} \mathrm{~cm}^{-2}$ to $29 \mathrm{~mW} \mathrm{~cm}^{-2}$. For conventional air-breathing microfluidic fuel cells with colaminar interface in the middle of the channel, high fuel concentrations increase the diffusive fuel crossover and decreases the performance [6]. In this design with the fuel reservoir, fuelelectrolyte interface is minimized and high fuel concentration can be used.

Unlike the flow-over planar anodes, depletion boundary layer is not formed over the reactive sites in this flow architecture and a uniform fuel concentration is provided over the electrode. Pressure of the fuel reservoir can be optimized according to the fuel concentration in the reservoir to overcome the mass transport limitations and to improve the fuel utilization.

$<$ Figure 6>

$<$ Figure 7>

To observe the long-term performance of the air-breathing microfluidic fuel cell, chronoamperometry test was conducted for cells running on $1 \mathrm{M}$ and $3 \mathrm{M}$ formic acid, as shown in Figure 8. For the case of using $1 \mathrm{M}$, the reservoir containing $0.8 \mathrm{ml}$ formic acid was pressurized slightly higher than $3 \mathrm{M}$ fuel to avoid mass-transport limited operation. An average current density of $68.8 \mathrm{~mA} \mathrm{~cm}^{-2}$ and a corresponding fuel utilization of $22 \%$ were achieved over a time period of 8 minutes, which is because of the limited volume of the fuel reservoir. The corresponding estimated fuel flow rate was $95 \mu 1 \mathrm{~min}^{-1}$. Performance was improved compare to the air-breathing cell with flow-through anode running on $100 \mu \mathrm{min}^{-1}$ of $1 \mathrm{M}$ formic acid with fuel utilization and average current density of $16.3 \%$ and 
$52.3 \mathrm{~mA} \mathrm{~cm}^{-2}$. In addition, using $1 \mathrm{ml}$ of $3 \mathrm{M}$ fuel, the cell produced an average current density of $86 \mathrm{~mA} \mathrm{~cm}^{-2}$ and a fuel utilization of $9 \%$ over a time span of ten minutes. The improved fuel utilization and current density were mainly obtained because of an enhanced mass transport through the anode. Since the catalyst layer is located on top of the electrode, $\mathrm{CO}_{2}$ bubbles were mostly produced in the reservoir and released easily to the chamber. Consequently, bubble formation in the channel is no longer a major issue which can hinder the fuel transport to the reactive sites. Furthermore, a continuous fuel supply is provided over the anode and the issue of low replenishment of fuel depletion layer does not exist. For conventional designs of air-breathing microfluidic fuel cells with flow-over anodes, fuel flow rate should be increased to overcome the slow mass transport to the depleted regions over the anode [19]. As a result, it makes the fuel utilization per single pass drops.

The large asperity observed in the cell current density running on $3 \mathrm{M}$ could be caused by bubble formation in the channel and the subsequent release through the outlet. Since catalyst layer was spread over the carbon paper, there is a chance for the catalyst particles to penetrate through the carbon-paper electrode and reach the other side. Consequently, formic acid can be oxidized over the electrode exposed to the flow channel resulting in bubble formation. A bubble can block the channel for a short while until it is washed to the channel outlet by the drag force of the electrolyte stream.

\section{$<$ Figure 8 $>$}

\section{Conclusion:}

In this paper, issue of bubble removal from the flow channel of air-breathing microfluidic fuel cell was addressed. Bubbles from formic acid electrooxidation were released to the fuel chamber. Unlike the flow-over anodes, depletion boundary layer over the anode was not formed and a uniform fuel concentration was supplied. In addition, since fuel was introduced 
to anode through the top side wall of the channel, the channel depth was decreased and the whole design could benefit from improved cell miniaturization and the subsequent lower Ohmic resistance compared to flow-over anodes.

It is worth mentioning that fuel density is raised as its concentration increases. In a verticallylayered liquid-liquid interface, where the dense stream is on top of the another stream with lower density, a faster mixing of two streams may occur [26]. Since in the current flow architecture, fuel after introduction to the channel though the porous anode is stacked over the the electrolyte stream, the chance of fuel crossover to the cathode side can be enhanced. For further developments, as a substitute for using higher electrolyte flow rate, a thin layer of Nafion can be coated over the cathode to decrease the cross-sectional area between the fuel and the active sites of the cathode as reported in [9].

Through optimizing the anode catalyst microstructure and the pressure of the fuel reservoir, higher fuel utilization per single pass can be achieved. To increase the applied pressure to the fuel chamber and to avoid the probable leakage from the electrolyte stream to the fuel channel, carbon paper-based anode can be treated to become hydrophobic.

The design allows the use of a fuel cartridge for passive delivery. The microfluidic fuel cell reported here provides a suitable platform for stacking which is necessary for practical applications. Several anodes in a stack can be connected to a single fuel reservoir containing high concentration of fuel through a microchannel network with integrated micropumps [27]. A numerical simulation of the active physico-electrochemical phenomena can provide better insights for further optimization of the anode permeability, fuel crossover to the cathode side, required gauge pressure and the relation between fuel utilization and power density.

\section{References}


[1] Ferrigno, R., Stroock, A.D., Clark, T.D., Mayer, M., Whitesides, G.M., Membraneless vanadium redox fuel cell using laminar flow. Journal of the American Chemical Society, 2002. 124(44): p. 12930-12931.

[2] Choban, E.R., Markoski, L.J., Wieckowski, A., Kenis, P.J.A., Microfluidic fuel cell based on laminar flow. Journal of Power Sources, 2004. 128(1): p. 54-60.

[3] Kjeang, E., Michel, R., Harrington, D.A., Djilali, N., Sinton, D., $A$ microfluidic fuel cell with flow-through porous electrodes. Journal of the American Chemical Society, 2008. 130(12): p. 4000-4006

[4] Wu, Z, Nguyen, N.T., Convective-diffusive transport in parallel lamination micromixers. Microfluidics and Nanofluidics, 2004. 1(3): p. 208-217

[5] Wu, Z., Nguyen, N.T., Rapid mixing using two-phase hydraulic focusing in microchannels. Biomedical Microdevices Journal, 2005, 7(1): p. 13-20

[6] Jayashree, R.S., Gancs, L., Choban, E.R., Primak, A., Natarajan, D., Markoski, L.J., Kenis, P.J.A., Air-breathing laminar flow-based microfluidic fuel cell. Journal of the American Chemical Society, 2005. 127(48): p. 16758-16759.

[7] Choban, E.R., Spendelow, J. S., Gancs, L., Wieckowski, A., Kenis, P. J. A., Membraneless laminar flow-based micro fuel cells operating in alkaline, acidic, and acidic/alkaline media. Electrochimica Acta, 2005. 50(27): p. 5390-5398.

[8] Brushett, F.R., Jayashree, R.S., Zhou, W.P., Kenis, P.J.A., Investigation of fuel and media flexible laminar flow-based fuel cells. Electrochimica Acta, 2009. 54(27): p. 7099-7105.

[9] Hollinger, A.S., Maloney, R.J., Jayashree, R.S., Natarajan, D., Markoski, L.J., Kenis, P.J.A., Nanoporous separator and low fuel concentration to minimize crossover in direct methanol laminar flow fuel cells. Journal of Power Sources, 2010. 195(11): p. 3523-3528.

[10] Kjeang, E., Djilali,N., Sinton, D., Microfluidic fuel cells: A review. Journal of Power Sources, 2008.

[11] Mousavi Shaegh, S.A., et al., Air-breathing membraneless laminar flowbased fuel cell with flow-through anode. International Journal of Hydrogen Energy, (0).

[12] Xuan, J., et al., Chaotic flow-based fuel cell built on counter-flow microfluidic network: Predicting the over-limiting current behavior. Journal of Power Sources, 2011. 196(22): p. 9391-9397.

[13] Mousavi Shaegh, S.A., Nguyen, N.T., Chan, S.H., A review on membraneless laminar flow-based fuel cells. International Journal of Hydrogen Energy, 2011. 36(9): p. 5675-5694.

[14] Park, H.B., et al., An H-shaped design for membraneless micro fuel cells. Electrochimica Acta, 2009. 54(18): p. 4416-4425. 
[15] López-Montesinos, P.O., et al., Design, fabrication, and characterization of a planar, silicon-based, monolithically integrated micro laminar flow fuel cell with a bridge-shaped microchannel cross-section. Journal of Power Sources, 2011. 196(10): p. 4638-4645.

[16] Salloum, K.S., Posner, J.D., Counter flow membraneless microfluidic fuel cell. Journal of Power Sources, 2010. 195(19): p. 6941-6944.

[17] Gervais, T. and K.F. Jensen, Mass transport and surface reactions in microfluidic systems. Chemical Engineering Science, 2006. 61(4): p. 1102-1121.

[18] Yoon, S.K., Fichtl, G.W., Kenis, P.J.A., Active control of the depletion boundary layers in microfluidic electrochemical reactors. Lab on a Chip - Miniaturisation for Chemistry and Biology, 2006. 6(12): p. 1516-1524.

[19] Mousavi Shaegh, S.A., Nguyen, N.T., Chan, S.H., An Air-breathing laminar flow-based formic acid fuel cell with porous planar anode: experimental and numerical investigations. Journal of Micromechanics and Microengineering, 2010. 20: p. 12.

[20] Jayashree, R.S., Yoon, Seong Kee, Brushett, Fikile R., LopezMontesinos, Pedro O., Natarajan, Dilip, Markoski, Larry J., Kenis, Paul J. A., On the performance of membraneless laminar flow-based fuel cells. Journal of Power Sources, 2010. 195(11): p. 3569-3578.

[21] Xuan, J., et al., Hydrodynamic focusing in microfluidic membraneless fuel cells: Breaking the trade-off between fuel utilization and current density. International Journal of Hydrogen Energy. In Press, Corrected Proof.

[22] Kjeang, E., McKechnie, Jonathan, Sinton, David, Djilali, Ned, Planar and three-dimensional microfluidic fuel cell architectures based on graphite rod electrodes. Journal of Power Sources, 2007. 168(2): p. 379390.

[23] Kjeang, E., Proctor, B.T.M., Brolo, A.G., Harrington, D.A., Djilali, N., Sinton, D., High-performance microfluidic vanadium redox fuel cell. Electrochimica Acta, 2007. 52(15): p. 4942-4946.

[24] Uhm, S., Lee, H.J., Lee, J, Understanding underlying processes in formic acid fuel cells. Phys. Chem. Chem. Phys., 2009(11): p. 9326 - 9336.

[25] Shyu, J.-C. and C.-L. Huang, Characterization of bubble formation in microfluidic fuel cells employing hydrogen peroxide. Journal of Power Sources, 2011. 196(6): p. 3233-3238.

[26] Xuan, J., et al., Towards orientation-independent performance of membraneless microfluidic fuel cell: Understanding the gravity effects. Applied Energy, 2012. 90(1): p. 80-86.

[27] Truong, T.Q. and N.T. Nguyen, A polymeric piezoelectric micropump based on lamination technology. Journal of Micromechanics and Microengineering, 2004. 14(4):p. 632 - 638. 


\section{List of Figures}

Figure 1. $G z-D a$ plot for some microfluidic fuel cells. Fuel and oxidant are $2 \mathrm{M}$ vanadium redox species $\left(\mathrm{V}^{2+} / \mathrm{V} 3+, \mathrm{VO}_{2}^{+} / \mathrm{VO}^{2+}\right)$ in $2 \mathrm{M}$ sulfuric acid as supporting electrolyte. No catalyst was used. Values in the parentheses refers to maximum power density, fuel utilization at cell potential of $0.8 \mathrm{~V}$

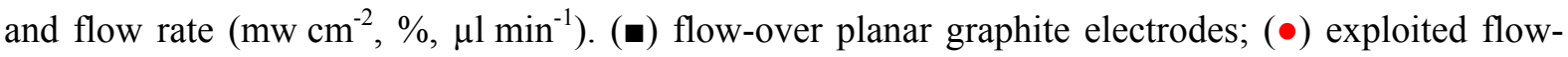
over porous carbon paper electrodes, while ( $\mathbf{\Delta})$ refers to flow-through porous carbon paper electrodes. To calculate $D a$ number for fuel stream, constant rate $(k)$ and diffusivity $(D)$ for $\mathrm{V}^{2+} / \mathrm{V} 3+$ were assumed to be $1.7 \times 10^{-7} \mathrm{~m} \mathrm{~s}^{-1}$ and $2.4 \times 10^{-11} \mathrm{~m}^{2} \mathrm{~s}^{-1}$, respectively [25].

Figure 2. Schematics of the two flow architectures, (a) with flow-over planar anode, and (b) with flow-through porous anode; reproduced after [9].

Figure 3. Air-breathing microfluidic fuel cell with fuel reservoir: (a) the exploded view, (b) the assembled cell and the operation of the air-breathing microfluidic fuel cell with a pressurized fuel reservoir and (c) the cross-sectional view of the cell. Electrolyte stream is introduced to the channel through an inlet. Channel length, depth and width are $30 \mathrm{~mm}, 0.5 \mathrm{~mm}$ and $3 \mathrm{~mm}$, respectively.

Figure 4. Open-circuit potential versus time after filling the fuel reservoir and applying pressure. Fuel concentration is $3 \mathrm{M}$.

Figure 5. Impedance spectra obtained at open-circuit potential. Depth of the fluidic channel is $0.5 \mathrm{~mm}$.

Figure 6. Polarization curves for the air-breathing microfluidic fuel cell with atmospheric and pressurized fuel reservoir at a gauge pressure of $3 \mathrm{mbar}$, both running on $3 \mathrm{M}$ formic acid at room temperature of $25^{\circ} \mathrm{C}$. Scanning rate was $5 \mathrm{mV} \mathrm{sec}{ }^{-1}$.

Figure 7. Polarization curves for an air-breathing microfluidic fuel cell with pressurized fuel reservoir, running on $1 \mathrm{M}$ and $3 \mathrm{M}$ formic acid at room temperature of $25^{\circ} \mathrm{C}$ and an applied pressure of 3 mbar. Scanning rate was $5 \mathrm{mV} \mathrm{sec}{ }^{-1}$. 
Figure 8. Chronoamperometry test for an air-breathing microfluidic cell with fuel reservoir containing $1 \mathrm{M}$ and $3 \mathrm{M}$ formic acid. Pressure of reservoir with $1 \mathrm{M}$ fuel was 3.3 mbar while the pressure of the reservoir with $3 \mathrm{M}$ was 3 mbar. 


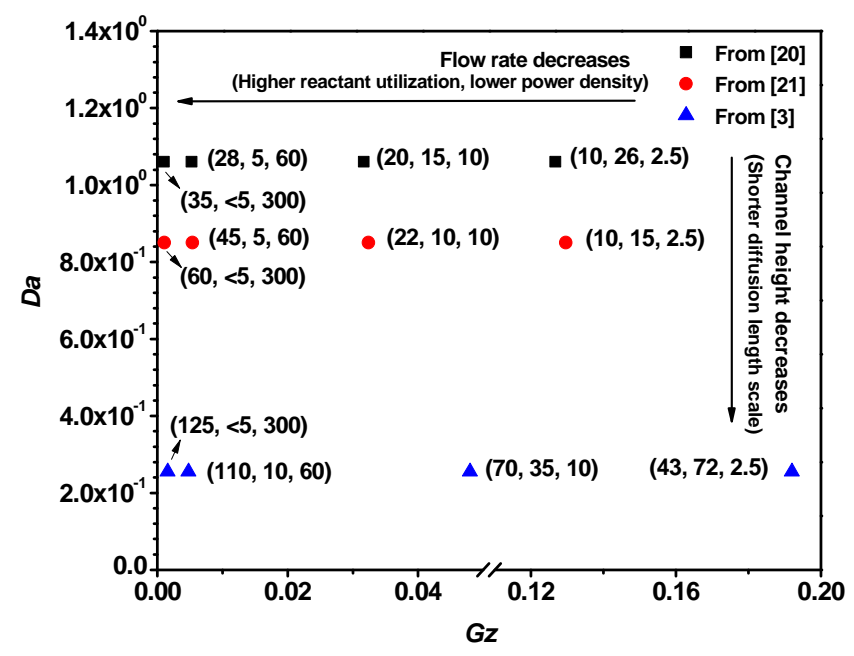

Figure 9. $G z-D a$ plot for some microfluidic fuel cells. Fuel and oxidant are $2 \mathrm{M}$ vanadium redox species $\left(\mathrm{V}^{2+} / \mathrm{V} 3+, \mathrm{VO}_{2}^{+} / \mathrm{VO}^{2+}\right)$ in $2 \mathrm{M}$ sulfuric acid as supporting electrolyte. No catalyst was used. Values in the parentheses refers to maximum power density, fuel utilization at cell potential of $0.8 \mathrm{~V}$ and flow rate $\left(\mathrm{mw} \mathrm{cm}{ }^{-2}, \%, \mu 1 \mathrm{~min}^{-1}\right)$. ( $)$ flow-over planar graphite electrodes; (•) exploited flowover porous carbon paper electrodes, while ( $\mathbf{\Delta})$ refers to flow-through porous carbon paper electrodes. To calculate $D a$ number for fuel stream, constant rate $(k)$ and diffusivity $(D)$ for $\mathrm{V}^{2+} / \mathrm{V} 3+$ were assumed to be $1.7 \times 10^{-7} \mathrm{~m} \mathrm{~s}^{-1}$ and $2.4 \times 10^{-11} \mathrm{~m}^{2} \mathrm{~s}^{-1}$, respectively [18]. 
(a)

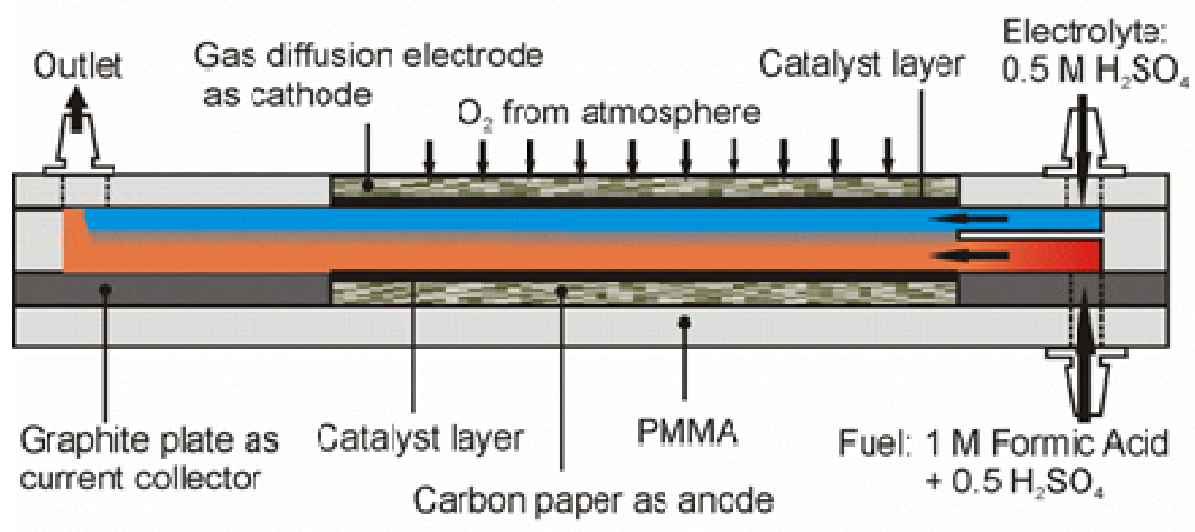

(b)

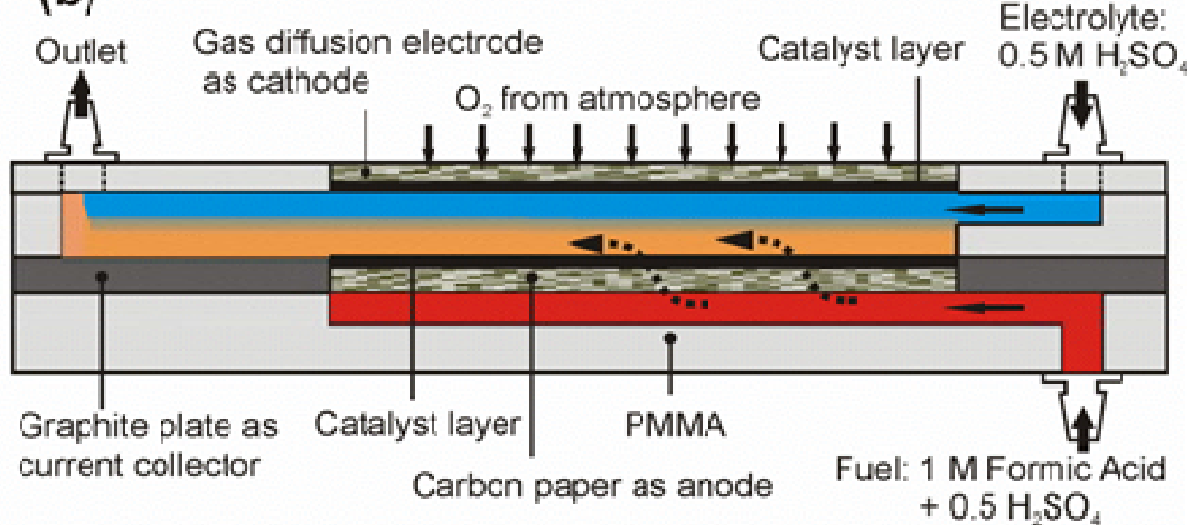

Figure 10. Schematics of the two flow architectures, (a) with flow-over planar anode, and (b) with flow-through porous anode; reproduced after [9]. 

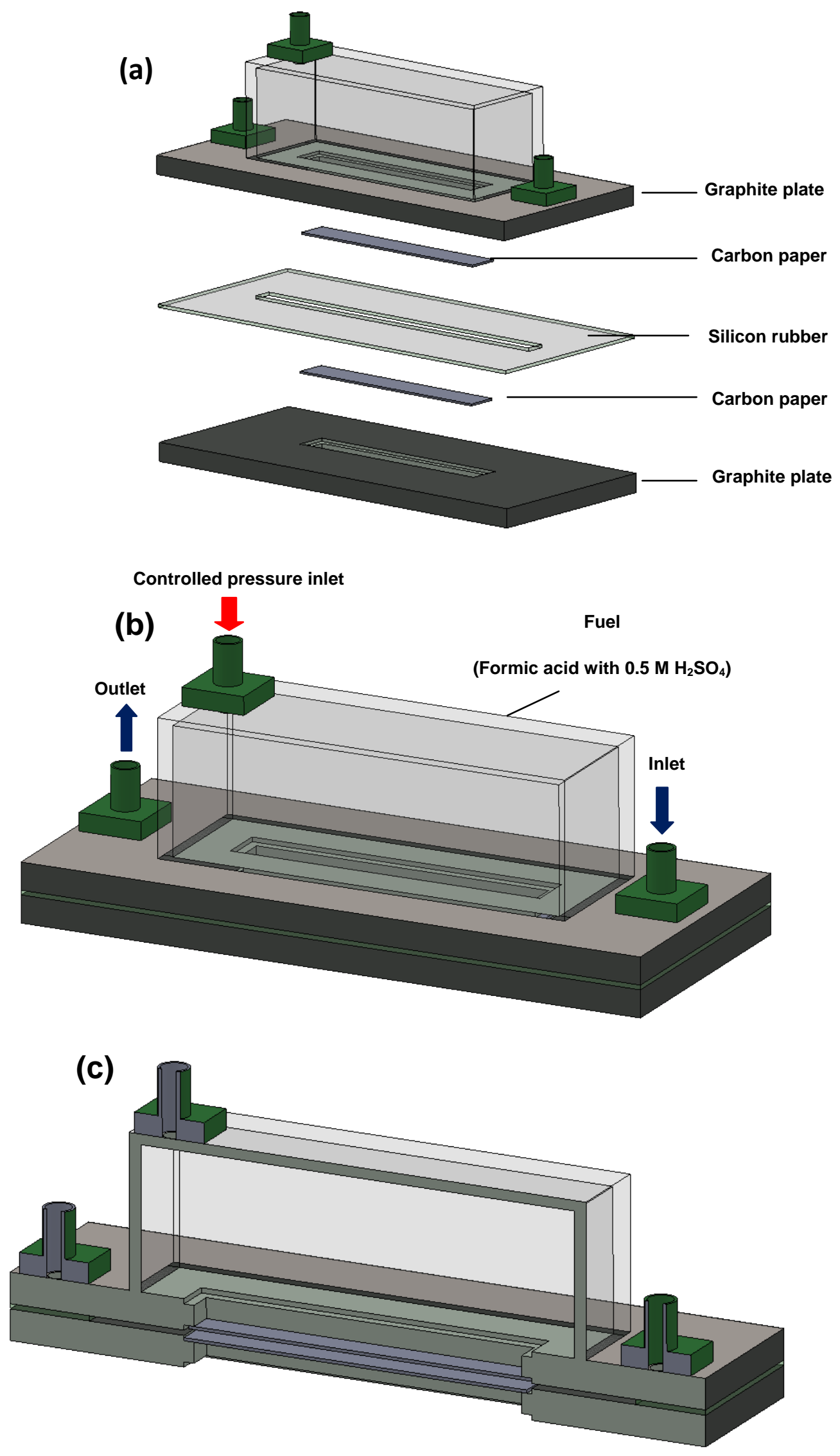
Figure 11. Air-breathing microfluidic fuel cell with fuel reservoir: (a) the exploded view, (b) the assembled cell and the operation of the air-breathing microfluidic fuel cell with a pressurized fuel reservoir, and (c) the cross-sectional view of the cell. Electrolyte stream is introduced to the channel through an inlet. Channel length, depth and width are $30 \mathrm{~mm}, 0.5 \mathrm{~mm}$ and $3 \mathrm{~mm}$, respectively. 


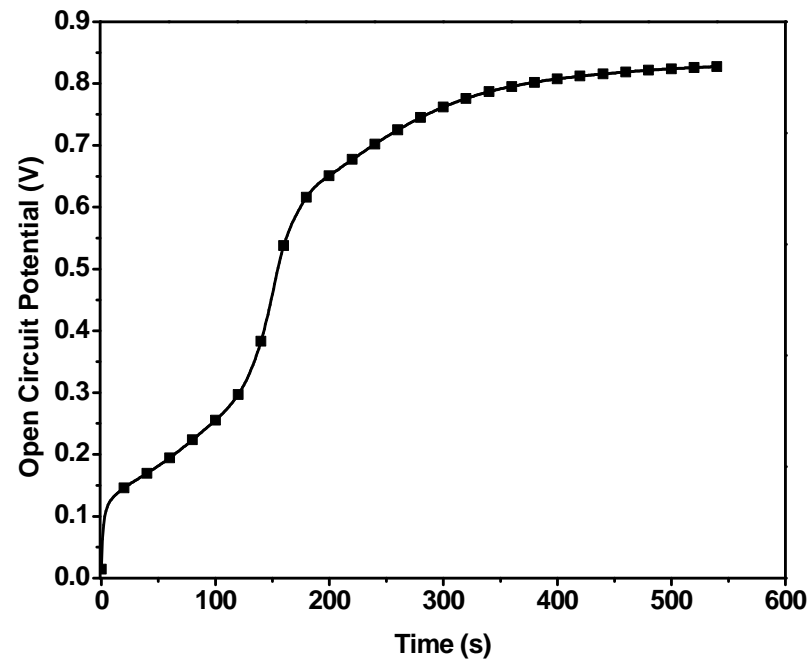

Figure 12. Open-circuit potential versus time after filling the fuel reservoir and applying pressure. Fuel concentration is $3 \mathrm{M}$. 


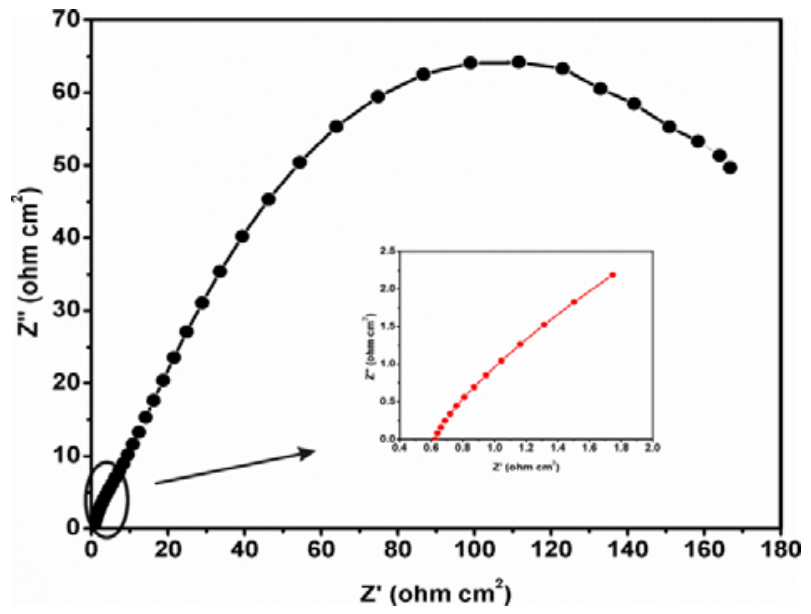

Figure 13. Impedance spectra obtained at open-circuit potential. Channel depth is $0.5 \mathrm{~mm}$. 


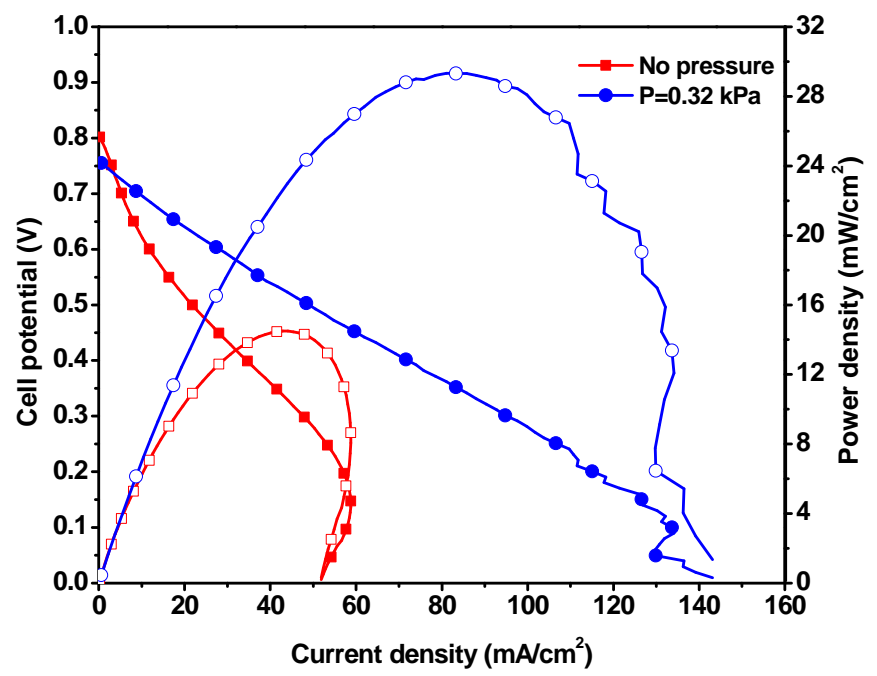

Figure 14. Polarization curves for the air-breathing microfluidic fuel cell with atmospheric and pressurized fuel reservoir at a gauge pressure of $3 \mathrm{mbar}$, both running on $3 \mathrm{M}$ formic acid at room temperature of $25^{\circ} \mathrm{C}$. Scanning rate was $5 \mathrm{mV} \mathrm{sec}^{-1}$. 


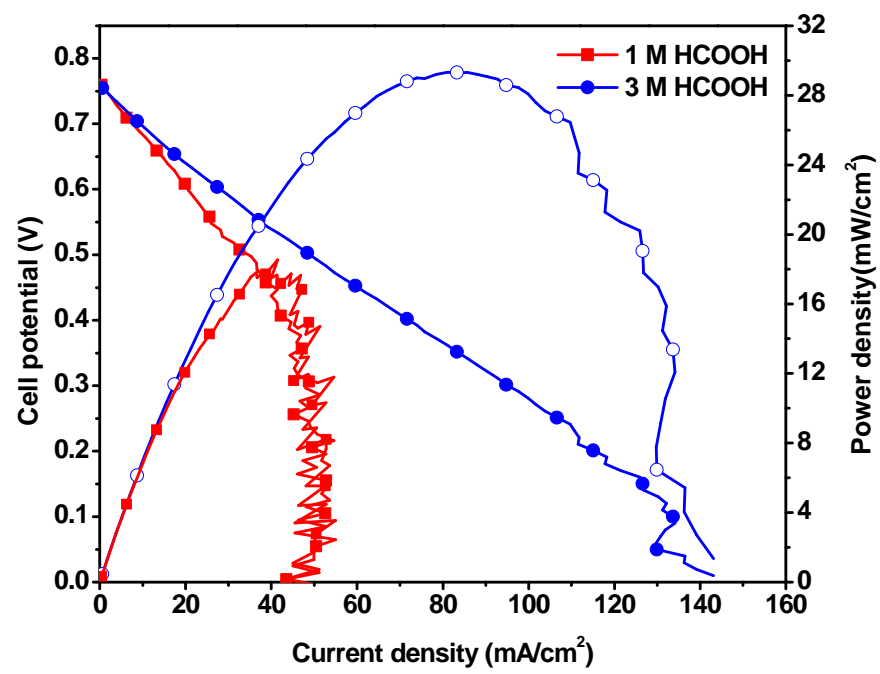

Figure 15. Polarization curves for an air-breathing microfluidic fuel cell with pressurized fuel reservoir, running on $1 \mathrm{M}$ and $3 \mathrm{M}$ formic acid at room temperature of $25^{\circ} \mathrm{C}$ and an applied gauge pressure of 3 mbar. Scanning rate was $5 \mathrm{mV} \mathrm{sec}^{-1}$. 


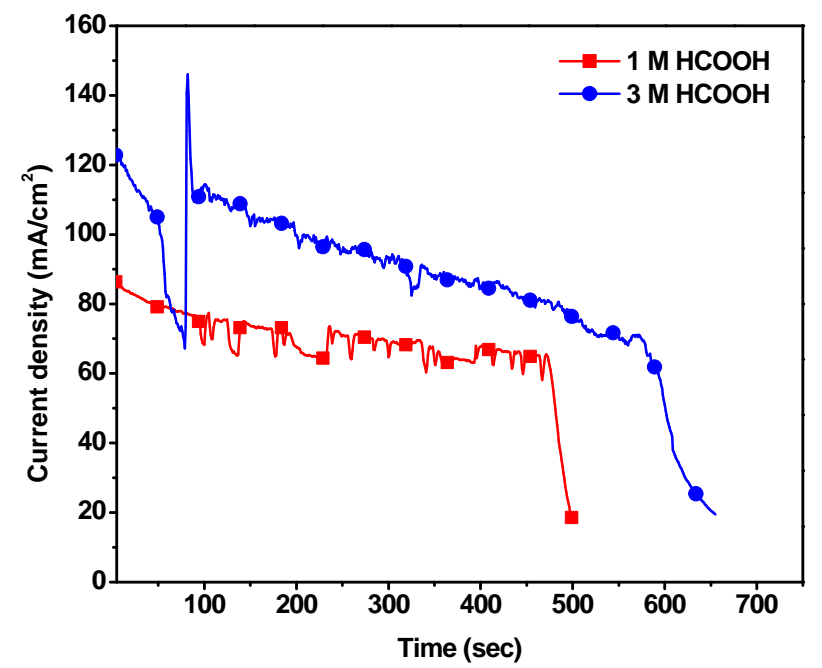

Figure 16. Chronoamperometry test for an air-breathing microfluidic cell with fuel reservoir containing $1 \mathrm{M}$ and $3 \mathrm{M}$ formic acid. Pressure of reservoir with $1 \mathrm{M}$ fuel was 3.3 mbar while the pressure of the reservoir with $3 \mathrm{M}$ was 3 mbar. 